\title{
Staged reconstruction brachytherapy has lower overall cost in recurrent soft-tissue sarcoma
}

\author{
Arash O. Naghavi, MD, MS*, Ricardo J. Gonzalez, MD2*, Jacob G. Scott, MD!, Youngchul Kim, PhD³, \\ Yazan A. Abuodeh, MD!, Tobin J. Strom, MD!, Michelle Echevarria, MD!, John E. Mullinax, MD², \\ Kamran A. Ahmed, MD', Lovis B. Harrison, MD', Daniel C. Fernandez, MD, PhD' \\ *Both authors contributed equally to this work. \\ 'Radiation Oncology. 2Sarcoma Department, ${ }^{3}$ Department of Biostatistics and Bioinformatics, H. Lee Moffitt Cancer Center and Research \\ Institute, Tampa, FL, USA
}

\begin{abstract}
Purpose: Adjuvant brachytherapy (AB) with immediate (IR) and staged reconstruction (SR) are distinct treatment modalities available for patients with recurrent soft tissue sarcoma (STS). Although SR may offer local control and toxicity benefit, it requires additional upfront procedures, and there is no evidence that it improves overall survival. With the importance of value-based care, our goal is to identify which technique is more cost effective.

Material and methods: A retrospective review of 22 patients with recurrent extremity STS treated with resection followed by $\mathrm{AB}$ alone. Hospital charges were used to compare the cost between SR and IR at the time of initial treatment, at 6-month intervals following surgery, and cumulative cost comparisons at 18 months.

Results: Median follow-up was 31 months. Staged reconstruction $(n=12)$ was associated with an 18 -month local control benefit $(85 \%$ vs. $42 \%, p=0.034)$, compared to IR $(n=10)$. Staged reconstruction had a longer hospital stay during initial treatment ( 10 vs. 3 days, $p=0.002)$, but at 18 months, the total hospital stay was no longer different (11 vs. 11 days). Initially, there was no difference in the cost of SR and IR. With longer follow-up, cost eventually favored SR, which was attributed primarily to the costs associated with local failure (LF). On multivariate analysis, cost of initial treatment was associated with length of hospital stay $(\sim 4.5 \mathrm{~K}$ per hospital day, $p<0.001)$, and at 18 months, the cumulative cost was $\sim 175 \mathrm{~K}$ lower with SR $(p=0.005)$ and $\$ 58 \mathrm{~K}$ higher with $\operatorname{LF}(p=0.02)$.

Conclusions: In recurrent STS, SR has a longer initial hospital stay when compared to IR. At 18 months, SR had lower rates of LF, translating to lower total costs for the patient. SR is the more cost-effective brachytherapy approach in the treatment of STS, and should be considered as healthcare transitions into value-based medicine.

J Contemp Brachytherapy 2017; 9, 1: 20-29 DOI: https://doi.org/10.5114/jcb.2017.65641
\end{abstract}

Key words: brachytherapy, cost, sarcoma, staged reconstruction, wound-vac.

\section{Purpose}

The treatment of extremity soft tissue sarcoma (STS) was historically driven by radical compartmental resections. The gold standard of treatment has shifted towards a multidisciplinary approach, utilizing adjuvant radiation (RT), and less radical surgery, to improve limb function and quality of life $[1,2,3,4,5]$. Changes in the landscape of healthcare are driving treatment considerations, and physicians must be mindful of value-based care. In STS, there is evidence that the extent of surgery [6] and the type of radiation [7] can affect both local control and health care cost of the patient.

In recurrent STS, the addition of adjuvant immediate reconstruction (IR) brachytherapy to surgery can offer a local control benefit [8], but may have high acute and long term toxicity rates requiring additional hospitalizations and procedures $[9,10,11,12,13,14,15]$. These complications may precipitate additional interventions that can increase costs after initial treatment $[16,17,18,19]$. Recent evidence has shown that utilizing staged reconstruction (SR) brachytherapy can minimize toxicity when compared to traditional IR [20]. Staged reconstruction brachytherapy uses a temporary closure during radiotherapy, such as negative pressure wound therapy (NPWT), minimizing radiation to the final closure $[9,10,11,12,13,14]$, thereby decreasing the risk of wound complications when compared to IR [20]. Since permanent pathology assessment occurs prior to final closure in SR, re-resection of close or positive tumor margins is possible without disrupting the healing closure. Previous studies from our center have shown that re-resection allowed for improved final mar-
Address for correspondence: Daniel C. Fernandez, MD, PhD, Radiation Oncology, H. Lee Moffitt Cancer Center and Research Institute, 12902 Magnolia Drive, Tampa, FL 33612, USA, phone: +1 813-745-8143, 凶e-mail: daniel.fernandez@moffitt.org
Received: 04.10 .2016

Accepted: 22.12.2016

Published: 28.02.2017 
gin status, which may contribute to a local control benefit in the SR group [20]. Since there is no difference in survival between these two techniques and many of the recurrences are amenable to re-excision [20], the additional cost of upfront procedures as required with SR may be unnecessary.

Upfront cost is expected to favor IR, since SR may accrue additional charges from NPWT expenses, hospitalization during radiation treatment, and the need for additional procedures (i.e., re-excisions, delayed reconstruction surgery, etc.). This is the first study that investigates cost of care for each reconstruction strategy, allowing for unique interpretation of long-term cost over the entire disease course, regardless of treatment modality. The purpose of this study is to analyze which reconstruction strategy (immediate vs. staged) is the most cost effective brachytherapy method for the treatment of recurrent STS.

\section{Material and methods}

\section{Population methods}

After Institutional Review Board approval, recurrent STS patients treated with postoperative adjuvant brachytherapy were assessed. Patient and tumor characteristics, in addition to outcome and toxicity were obtained by retrospective chart review. Only patients with non-metastatic recurrent extremity soft tissue sarcoma treated entirely at our institution, and $>12$ months of follow-up were included in this study to allow for consistent and adequate time to assess long-term cost and toxicity. Hospital charges accrued at our institution for each patient were obtained from the billing department, and patients hospitalized or treated elsewhere were excluded from this study. We defined chronic toxicity as persistent signs/symptoms at 1-year follow-up. Treatment included resection followed by the insertion of a single-plane of brachytherapy catheters, $1 \mathrm{~cm}$ apart in parallel. This was then followed by adjuvant brachytherapy and the wound was either closed at the initial operation (IR) or at a second operation (SR). Details of the reconstruction technique, use of NPWT, and treatment planning were previously described [20]. High-dose-rate adjuvant brachytherapy was delivered with ${ }^{192}$ Ir to 32-45 Gy BID in 8-10 fractions.

Toxicities were identified from medical records following surgery, and were determined by new signs or symptoms noted in the medical record, in addition to changes in patient medications (i.e., opioids, gabapentin, etc.). Toxicity was categorized as: fracture, persistent toxicity, chronic toxicity, and wound complications. Persistent toxicity, defined as unrelieved $>30$ days after surgery, includes persistent edema and non-healing wound. Chronic toxicity, persisting $>1$ year after surgery, includes chronic arthropathy, pain, neuropathy, and edema. Wound complications were further subdivided into seroma, infection, and wound dehiscence. Arthropathy was determined based on the limited limb function noted on history and physical examination. Pain was defined as persistent or worsening, noted by the patient, or by increases in pain medication prescribed. Neuropathy was defined by findings on history as well as physical examination findings. Fracture was noted as a complication if the event occurred in the treated area any time after surgery.

\section{Statistical methods}

\section{Outcome analysis}

Staged reconstruction and IR were compared in regards to patient/tumor characteristics, treatment, toxicity, and cost via Pearson $\chi^{2}$ association test, Fisher's exact test, and Mann-Whitney $U$ test for univariate analysis (UVA) when appropriate. Time-to-event outcomes were defined as the duration of time from the date of resection to an event or last follow-up as a censoring date. These events include local failure (LF), amputation, or distant metastasis (DM), which define the rate of local control (LC), limb preservation (LP), and freedom-from distant metastasis (FFDM), respectively. Differences in the timeto-event outcomes between SR and IR were illustrated by Kaplan-Meier survival curves and comparisons were made via log-rank test.

In patients with 18 months of follow-up $(n=17)$, the total number of procedures (skin grafts, flaps, NPWTs, primary closures, and additional debridement after closure) and hospitalizations (hospitalization for antibiotics, hospital days, admissions) were also compared between the SR and IR cohort via Mann U Whitney.

\section{Cost analysis}

Hospital charges accrued from our institution and corresponding dates were obtained from our billing department, including all charges during inpatient and outpatient visits. Charges accrued were adjusted for inflation to 2015 with a Consumer Price Index inflation calculator provided by the Bureau of Labor Statistics (www. bls.gov). To limit institutional variability in cost, patients that were hospitalized or received treatment at an outside facility were excluded from this study. The cost comparison of patients with SR vs. IR, local failure vs. no local failure, and amputation vs. no amputation, were calculated via Mann-Whitney $U$ for initial treatment of recurrence (termed "initial treatment": all charges accrued from the time of surgery to first follow-up, approximately 1 -month following resection), at each 6 -month block following surgery (all charges accrued 1 to 6,6 to 12, 12 to 18 , and 18 to 24 months following surgery), and for cumulative charges at 18 months. Follow-up charges at each 6-month block were calculated only for patients that completed that particular follow-up block, to offset cost discrepancies associated with shorter follow-up. Cost was categorized into follow-up periods to help determine where changes in cost may arise and whether they temporally correlate with specific events (i.e., local failure or amputation). Cumulative charges at 18 months capture the majority of local failure and amputation events, while allowing the inclusion of $77 \%$ of the cohort $(n=17)$.

Predictors of cost assessed at initial treatment (from surgery to first follow-up) and at 18 months includes: patient characteristics (gender, previous radiation, Karn- 
ofsky performance status [KPS], vascular disease, diabetes, smoking pack years [continuous], age [continuous]), tumor characteristics (primary site [upper vs. lower extremity], tumor size [continuous], FNCLCC grade [G3 vs. G1/2]), and treatment (final margin status [R0 vs. R1 defined by ink margin], reconstruction [SR vs. IR], final closure [flap vs. primary closure], and hospital stay at initial treatment [initial treatment analysis only]) were included in a multiple linear regression multivariate analysis (MVA). To quantify the influence that events (local failure or amputation), hospitalizations/admissions, and procedures have on cost at 18 months, these variables were also analyzed via multiple linear regression MVA. Two-sided $p$-values and the level of significance of 0.05 were used for defining statistical significance, with all analyses performed using SPSS v 22 (IBM, Armonk, NY, USA).

\section{Results}

\section{Patient, tumor, and treatment characteristics}

From 1999-2015, 145 patients underwent $A B$ for soft tissue sarcoma at our institution. Of these patients, 22 patients met the inclusion criteria with treatment spanning from 2008 to 2015 . Of these patients, 12 (55\%) had SR and 10 (45\%) had IR, with treatment beginning as early as 2008 . The cohort has a median follow-up of 31 months. The majority of patients consisted of lower extremity disease $(64 \%)$, FNCLCC grade $3(64 \%)$, and had been previously irradiated $(77 \%)$. The patient and tumor characteristics were relatively well balanced between SR and IR (Table 1). At initial treatment, the SR cohort had a higher percentage of NPWT use $(75 \%$ vs. $0 \%, p<0.001)$ and final closure with flap reconstruction ( $83 \%$ vs. $20 \%$, $p=0.008)$, when compared to IR.

\section{Reconstruction effect on clinical outcome}

The overall local failure, amputation, and distant metastasis rates were $36 \%, 36 \%$, and $18 \%$, respectively. The overall actuarial rates of 2-year local control, limb preservation, and FFDM were $63 \%, 67 \%$, and $87 \%$, respectively. At 24 months, SR was associated with a local control benefit $(83 \%$ vs. $40 \%, p=0.039)$ (Figure $1 \mathrm{~A})$, a trending limb preservation benefit ( $83 \%$ vs. $48 \%, p=0.054$ ) (Figure 1B), and no association with FFDM ( $88 \%$ vs. $86 \%, p=0.94)$.

When comparing the difference in toxicity, IR had higher rates of chronic pain ( $50 \%$ vs. $8 \%, p=0.056)$, persistent edema (> 30 days: $60 \%$ vs. $17 \%, p=0.074$ ), chronic edema ( $>1$ year: $50 \%$ vs. $8 \%, p=0.056)$, and a trend toward higher infection (70\% vs. $33 \%, p=0.198)$, when compared to SR on UVA (Table 2).

Staged reconstruction was associated with a longer initial hospital stay (10 vs. 3 days, $p=0.002)$, but after 18 months of follow-up, there was no longer a difference in the total hospital stay ( 11 vs. 11 days, $p=0.96)$, with SR averaging 1 fewer admission than IR ( 2 vs. $3, p=0.48$ ). At 18 months following resection, there was no statistical difference in the number of total surgical procedures, hospitalizations, or admissions between the two cohorts (Table 3).

\section{Reconstruction and outcomes association with cost}

Overall, the cost of initial treatment was $\$ 88,460$ (\$48,675 to $\$ 206,263)$ with no significant difference between IR and SR $(\$ 79,216$ vs. $\$ 96,163, p=0.72)$. The average accrued cost following IR was modestly elevated during months 1 to 6 ( $\$ 43,494$ vs. $\$ 26,065, p=0.5$ ) and 6 to 12 ( $\$ 65,971$ vs. $\$ 23,464$, $p=0.159)$, with a significantly higher cost during months 12 to 18 (\$68,061 vs. $\$ 9,110, p=0.046)$, compared to SR (Figure $2 \mathrm{~A})$.

Local failure and amputation predominantly occurred during the first 12 to 18 months following surgery. All local failures $(n=8)$ occurred within the first 18 months following surgery, with 7 (88\%) during the first 12 months. Patients that underwent a local failure also experienced a rise in cost, with a significant increase 6 to 12 months following surgery (vs. no local failure: $\$ 90,150$ vs. $\$ 15,720$, $p=0.003$ ) (Figure 2B). Although a high percentage of amputations occurred during the first 18 months $(n=7$, $88 \%$ ), there was no significant difference in cost between patients amputated vs. non-amputated (Figure 2C). At 12 months, local failures had occurred in a high percentage of IR patients $(50 \%)$. After excluding patients with local failure, there was no longer a significant difference in cost between the two cohorts (all $p>0.05$ ) (Figure 3).

\section{Predictors of initial treatment cost}

No patient, tumor, or treatment characteristics predicted for cost of initial treatment on MVA. The length of hospital stay was the only factor independently associated with the cost of initial treatment, with an increase of $\sim \$ 400$ per additional hospital day (95\% CI \$3K to \$6K, $p<0.001)$, on MVA. Staged reconstruction, when compared to IR, had a significantly longer length of stay for initial surgery (10 vs. 3 days, $p<0.001)$, with no discernable difference in initial treatment cost $(p=0.72)$.

\section{Predictors of total cost at 18 months}

The predictors of total cost at 18 months include patient characteristics, tumor characteristics, and initial treatment. At 18 months, SR independently predicted for decrease in cost of $\sim \$ 178,000$ (95\% CI $\$ 69 \mathrm{~K}$ to $\$ 286 \mathrm{~K}$, $p=0.005)$. In addition, there was decreased cost with treatment of the lower extremity (beta (regression slope) $=-\$ 127 \mathrm{~K}, 95 \% \mathrm{CI}-\$ 240 \mathrm{~K}$ to $-\$ 13 \mathrm{~K}, p=0.033)$, and an increased cost in diabetics (beta $=\$ 542 \mathrm{~K}, 95 \% \mathrm{CI} \$ 211 \mathrm{~K}$ to $\$ 873 \mathrm{~K}, p=0.005), \mathrm{BMI} \geq 30 \mathrm{~kg} / \mathrm{m}^{2}$ (beta $=\$ 368 \mathrm{~K}, 95 \% \mathrm{CI}$ $\$ 200 \mathrm{~K}$ to $535 \mathrm{~K}, p=0.001$ ), and FNCLCC (grade 3 vs. grade $1 / 2$ : beta $=\$ 288 \mathrm{~K}, 95 \%$ CI $\$ 128$ to $\$ 447 \mathrm{~K}, p=0.003$ ), on MVA.

The effects that clinical outcome and toxicity have on the total cost at 18 months were evaluated on MVA. This includes local failure, hospital admissions, and total procedures performed (i.e., number of primary closures, skin grafts, NPWTs, flaps, or amputations). On MVA, local failure predicted for $\sim \$ 58,000$ increase in cost (95\% CI $\$ 11 \mathrm{~K}$ to $\$ 104 \mathrm{~K}, p=0.02)$. In addition, there was an increase in cost of $\sim \$ 10,000$ for each day hospitalized (95\% CI $\$ 7 \mathrm{~K}$ to $\$ 12 \mathrm{~K}, p<0.001$ ), and an additional $\$ 79,000$ for each hospitalization for antibiotics (95\% CI $\$ 62 \mathrm{~K}$ to \$96K, $p<0.001)$. 
Table 1. Comparing initial patient, tumor, and treatment characteristics between staged (SR) and immediate reconstruction (IR)

\begin{tabular}{|c|c|c|c|}
\hline Factor & $\begin{array}{l}\text { Total }(n=22) ; \\
\text { median (range) }\end{array}$ & $\begin{array}{c}\text { SR }(n=12) ; \\
\text { median (range) }\end{array}$ & $\begin{array}{c}\text { IR }(n=10) ; \\
\text { median (range) }\end{array}$ \\
\hline Age (years) & $67(23-94)$ & $72(30-86)$ & $61(23-94)$ \\
\hline Time from previous surgery (months) & $19(2-231)$ & $20(2-119)$ & $19(2-231)$ \\
\hline Number of prior resections & $1(1-4)$ & $1(1-3)$ & $1(1-4)$ \\
\hline Tumor size $(\mathrm{cm})$ & $4(2-14.5)$ & $3.9(2.1-14.5)$ & $5.3(2-8)$ \\
\hline KPS at surgery & $95(80-100)$ & $100(90-100)$ & $90(80-100)$ \\
\hline Pack-years continuous & $0(0-50)$ & $0(0-50)$ & $0(0-45)$ \\
\hline Current RT dose (Gy) & $35(32-45)$ & $35(35-35)$ & $35(32-45)$ \\
\hline \multirow[t]{2}{*}{ Follow-up (months) } & $31(12-79)$ & $27(12-63)$ & $36(13-79)$ \\
\hline & Total; No. (\%) & SR; No. (\%) & IR; No. (\%) \\
\hline \multicolumn{4}{|l|}{ NPWT closure* } \\
\hline No NPWT & $13(59 \%)$ & $3(25 \%)$ & $10(100 \%)$ \\
\hline NPWT & $9(41 \%)$ & $9(75 \%)$ & $(0 \%)$ \\
\hline \multicolumn{4}{|l|}{ Final closure* } \\
\hline Primary closure & $10(46 \%)$ & $2(17 \%)$ & $8(80 \%)$ \\
\hline Flap & $12(55 \%)$ & $10(83 \%)$ & $2(20 \%)$ \\
\hline \multicolumn{4}{|l|}{ Gender } \\
\hline Female & $9(41 \%)$ & $5(42 \%)$ & $4(40 \%)$ \\
\hline Male & $13(59 \%)$ & $7(58 \%)$ & $6(60 \%)$ \\
\hline \multicolumn{4}{|l|}{ Race } \\
\hline White & $21(96 \%)$ & $12(100 \%)$ & $9(90 \%)$ \\
\hline Black & $1(5 \%)$ & $0(0 \%)$ & $1(10 \%)$ \\
\hline \multicolumn{4}{|l|}{ Marital status } \\
\hline Not married & $4(18 \%)$ & $2(17 \%)$ & $2(20 \%)$ \\
\hline Married & $18(82 \%)$ & $10(83 \%)$ & $8(80 \%)$ \\
\hline \multicolumn{4}{|l|}{ County of residence } \\
\hline Other county & $20(91 \%)$ & $11(92 \%)$ & $9(90 \%)$ \\
\hline County of hospital & $2(9 \%)$ & $1(8 \%)$ & $1(10 \%)$ \\
\hline \multicolumn{4}{|l|}{ Primary site } \\
\hline Upper extremity & $8(36 \%)$ & $4(33 \%)$ & $4(40 \%)$ \\
\hline Lower extremity & $14(64 \%)$ & $8(67 \%)$ & $6(60 \%)$ \\
\hline \multicolumn{4}{|l|}{ Tumor differentiation } \\
\hline Well & $1(5 \%)$ & $0(0 \%)$ & $1(10 \%)$ \\
\hline Moderate & $4(18 \%)$ & $3(25 \%)$ & $1(10 \%)$ \\
\hline Poor/Undifferentiated & $17(77 \%)$ & $9(75 \%)$ & $8(80 \%)$ \\
\hline \multicolumn{4}{|l|}{ Re-irradiation } \\
\hline No prior radiation & $5(23 \%)$ & $3(25 \%)$ & $2(20 \%)$ \\
\hline Re-irradiation & $17(77 \%)$ & $9(75 \%)$ & $8(80 \%)$ \\
\hline
\end{tabular}


Table 1. Cont.

\begin{tabular}{|c|c|c|c|}
\hline & Total; No. (\%) & SR; No. (\%) & IR; No. (\%) \\
\hline \multicolumn{4}{|c|}{ Margin status (ink margin) } \\
\hline RO & $16(73 \%)$ & $10(83 \%)$ & $6(60 \%)$ \\
\hline R1 & $6(27 \%)$ & $2(17 \%)$ & $4(40 \%)$ \\
\hline \multicolumn{4}{|l|}{ FNCLCC grade } \\
\hline G1 & $1(5 \%)$ & $0(0 \%)$ & $1(10 \%)$ \\
\hline $\mathrm{G} 2$ & $7(32 \%)$ & $5(42 \%)$ & $2(20 \%)$ \\
\hline G3 & $14(64 \%)$ & $7(58 \%)$ & $7(70 \%)$ \\
\hline \multicolumn{4}{|l|}{ Diabetes } \\
\hline No & $21(96 \%)$ & $11(92 \%)$ & $10(100 \%)$ \\
\hline Yes & $1(5 \%)$ & $1(8 \%)$ & $0(0 \%)$ \\
\hline \multicolumn{4}{|l|}{ Tobacco status } \\
\hline Current & $2(9 \%)$ & $2(17 \%)$ & $0(0 \%)$ \\
\hline Former & $6(27 \%)$ & $2(17 \%)$ & $4(40 \%)$ \\
\hline Never & $14(64 \%)$ & $8(67 \%)$ & $6(60 \%)$ \\
\hline \multicolumn{4}{|c|}{ Pack-years categorized } \\
\hline None & $14(64 \%)$ & $8(67 \%)$ & $6(60 \%)$ \\
\hline$<20$ pack-years & $2(9 \%)$ & $1(8 \%)$ & $1(10 \%)$ \\
\hline$\geq 20$ pack-years & $6(27 \%)$ & $3(25 \%)$ & $3(30 \%)$ \\
\hline \multicolumn{4}{|l|}{ Vascular disease } \\
\hline No & $12(55 \%)$ & $7(58 \%)$ & $5(50 \%)$ \\
\hline Yes & $10(46 \%)$ & $5(42 \%)$ & $5(50 \%)$ \\
\hline \multicolumn{4}{|l|}{ BMI $\left(\mathrm{kg} / \mathrm{m}^{2}\right)$} \\
\hline$<30$ & $12(55 \%)$ & $6(50 \%)$ & $6(60 \%)$ \\
\hline$\geq 30$ & $10(46 \%)$ & $6(50 \%)$ & $4(40 \%)$ \\
\hline
\end{tabular}

$B M I$ - body mass index $\left(\mathrm{kg} / \mathrm{m}^{2}\right), G y$ - Gray, $\mathrm{cm}$ - centimeter, IR - immediate reconstruction, KPS - Karnofsky performance status, NPWT - negative pressure wound therapy, No. - number, RT-radiation, SR - staged reconstruction

*Statistically significant difference between staged reconstruction and immediate reconstruction $(p<0.05)$

\section{Discussion}

In the rapidly evolving healthcare landscape, it is increasingly important that physicians be cognizant of cost effectiveness, especially when various treatment options are available. In addition to cost, it is critical we implement treatments that will optimize disease control, survival, and patient toxicity. This forms a fundamental philosophy of focusing our efforts on value-based care approaches. In the setting of STS, treatment strategies for the primary disease may vary in their local control, but rarely differ in survival, as many patients are amenable to salvage surgery. Soft tissue sarcoma treatment has therefore shifted to a multimodality approach with more conservative surgery in an effort to minimize toxicity and optimize quality of life $[1,2,3,4]$. In the era of bundle payments, in addition to efficacy and safety, physicians must also consider cost effectiveness when choosing a treatment approach. When considering cost, we must account for factors that influence both the immediate and long-term expense of treatment. In STS, there is evidence that the type of radiation [7] and extent of surgery [6] can influence immediate and long-term costs, respectively. To our knowledge, this is the first study to evaluate the difference in initial and long-term costs of adjuvant brachytherapy techniques (SR vs. IR), for the treatment of recurrent STS. Our study suggests that SR may have longer initial hospital stay, a factor predictive of initial cost, but at 18 months, the reduction of toxicity and increased local control makes SR a more cost effective treatment overall.

Factors that may influence charge accrual during initial treatment include: length of hospitalization, number of procedures, and type of procedures $[16,17,18,19]$. For 

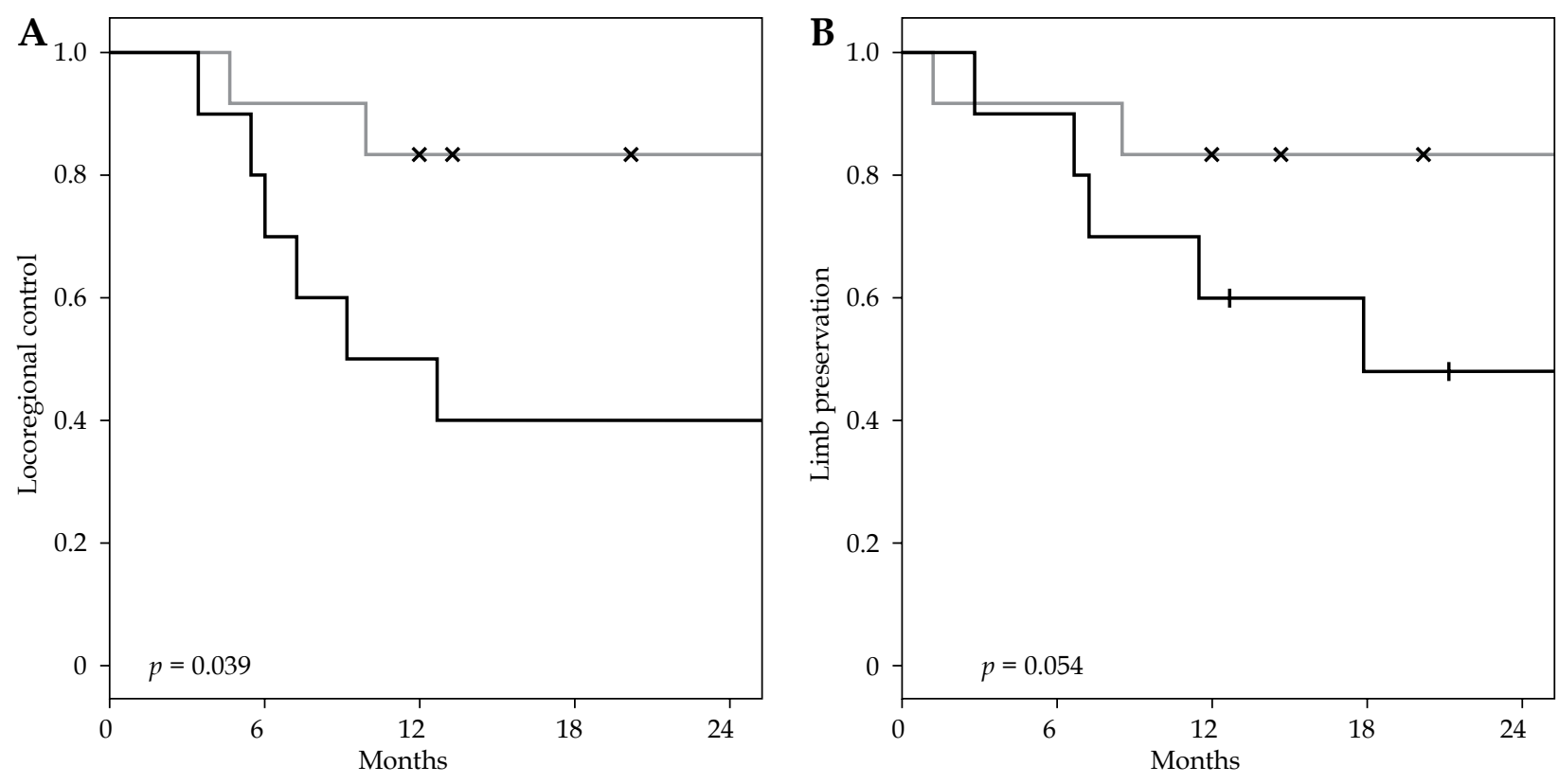

— immediate $\longrightarrow$ staged I immediate-censored $\times$ staged-censored

Fig. 1. Kaplan Meier comparison between staged reconstruction (SR) and immediate reconstruction (IR), for (A) local control (LC), and (B) limb preservation (LP)

Table 2. Comparison of toxicity between staged (SR) and immediate reconstruction (IR) (UVA)

\begin{tabular}{lccc}
\hline Factor & Total; No. $(\%)$ & SR $(n=12) ;$ No. $(\%)$ & IR $(n=10) ;$ No. (\%) \\
\hline Persistent edema $(>30$ days) & $8(36 \%)$ & $2(17 \%)$ & $6(60 \%)$ \\
\hline Chronic edema $\left(>1\right.$ year) $^{*}$ & $6(27 \%)$ & $1(8 \%)$ & $5(50 \%)$ \\
\hline Chronic pain $^{*}$ & $6(27 \%)$ & $1(8 \%)$ & $5(50 \%)$ \\
\hline Infection & $11(50 \%)$ & $4(33 \%)$ & $7(70 \%)$ \\
\hline Chronic arthropathy & $4(18 \%)$ & $1(8 \%)$ & $3(30 \%)$ \\
\hline Chronic neuropathy & $1(5 \%)$ & $1(8 \%)$ & $1(10 \%)$ \\
\hline Fracture & $1(5 \%)$ & $0(0 \%)$ & $7(70 \%)$ \\
\hline Wound complications & $16(73 \%)$ & $9(75 \%)$ & $2(20 \%)$ \\
\hline Seroma & $4(18 \%)$ & $2(17 \%)$ & $7(70 \%)$ \\
\hline Dehiscence & $12(55 \%)$ & $5(42 \%)$ & $2(20 \%)$ \\
\hline Non-healing wound & $3(14 \%)$ & $1(8 \%)$ & \\
\hline$R$ - & & & $1(20 \%)$ \\
\hline
\end{tabular}

IR-immediate reconstruction, No. - number, $S R$ - staged reconstruction

*Trending or significant on univariate analysis $(p<0.1)$

example, Petruzzelli et al. noted a cost difference in regards to reconstructive modality [21]. They found that flap closure had increases in cost and length of hospital stay when compared to primary closure [21]. Although, our study showed longer initial hospital stay (10 vs. 3 days) and higher rates of flap closures $(83 \%$ vs. $55 \%, p=0.003)$ in the SR group, there was no significant difference in initial cost $(\$ 96,163$ vs. $\$ 79,216)$ when compared to IR. Since initial hospital stay was independently associated with initial treatment cost, we believe that the study may be underpowered to detect the higher initial costs in the SR group.
After the initial treatment, the cost is influenced by tumor recurrence and patient toxicity, requiring additional procedures and hospitalizations $[17,19]$. Consistent with our previous study [20], this study also found that SR predicted for a local control, limb preservation, and a toxicity benefit when compared to IR. Staged reconstruction minimizes radiation to the final closure and utilizes NPWT for temporary closure $[20,22,23,24,25]$, both of which can improve wound healing $[26,27,28]$. In STS, Sakellariou et al. showed that the use of NPWT after surgery can improve length of hospitalization, complication, and infection rates, and the total cost of wound healing treatment 
Table 3. Comparison of procedures, hospitalizations, and admissions between staged (SR) and immediate reconstruction (IR) at 18 months

\begin{tabular}{|c|c|c|c|}
\hline Factor & $\begin{array}{c}\text { Total ( } n=17) ; \\
\text { median (range) }\end{array}$ & $\begin{array}{c}\text { SR }(n=9) ; \\
\text { median (range) }\end{array}$ & $\begin{array}{c}\mathrm{IR}(n=8) ; \\
\text { median (range) }\end{array}$ \\
\hline Hospital stay of initial treatment (days) ${ }^{\star *}$ & $7(1-31)$ & $10(5-31)$ & $3(1-10)$ \\
\hline Number of skin grafts & $1(0-2)$ & $1(0-2)$ & $1(0-1)$ \\
\hline Number of flaps & $1(0-2)$ & $1(0-2)$ & $1(0-1)$ \\
\hline Number of NPWTS & $1(0-5)$ & $1(0-5)$ & $0(0-2)$ \\
\hline Number of primary closures & $1(0-2)$ & $1(0-1)$ & $1(0-2)$ \\
\hline Number of hospitalizations for antibiotics alone & $0(0-5)$ & $0(0-1)$ & $0(0-5)$ \\
\hline Additional debridement & $1(0-5)$ & $1(0-5)$ & $1(0-3)$ \\
\hline Total hospital stay (days) & $11(2-31)$ & $11(3-21)$ & $11(2-31)$ \\
\hline Total admissions & $2(1-7)$ & $2(1-3)$ & $3(1-7)$ \\
\hline
\end{tabular}

(NPWT vs. No NPWT: $\$ 4,867$ vs. $\$ 11,680, p=0.018$ ). In our study, the use of NPWT and improved toxicity in the SR cohort may also contribute to the cost benefit following initial treatment.

In our previous study, SR allowed re-excision of close margins after final pathologic assessment, which resulted in an improvement in the final margin status over IR. After accounting for margin status, SR was independently associated with a local control benefit on MVA (HR $=0.25,95 \%$ CI: $0.08-0.8, p=0.02)$ [20]. Although this is a small retrospective study $(n=40)$, it suggests that there may be a benefit to SR that is likely multifactorial in nature [20]. The other hypothetical local control benefits with SR include faster time to adjuvant RT $[29,30]$ and a decrease in wound hypoxia with NPWT, which may lead to improved radiation efficacy [31,32]. Final margin status is considered the primary contributor to SR's local control benefit and likely played a role in the lower cost noted with SR. Although, there was no difference in the margin status between SR and IR in our current analysis, it should be noted that this is a subset of patients from our previous study, and is likely underpowered to detect a significant difference in margin status between these two cohorts [20].

In this study, all local failures occurred during the first 18 months of follow-up, with a significant difference in cost during months 6 to 12 following surgery for patients that failed. The rise in cost associated with local failure is consistent with the rise in IR cost seen in the months following initial treatment. After excluding patients with local failure, there was no longer a difference in cost between SR and IR. This suggests that local failure is likely the primary contributor to the rising costs in IR following surgery. At 18 months, SR and local failure independently predicted for total cost, with $\$ 178 \mathrm{~K}$ cost benefit with SR and an additional cost of $\$ 58 \mathrm{~K}$ in patients with local failure. Staged reconstruction had a higher initial hospital stay, NPWT use, and flap closure, but at 18 months, there was no difference in total hospital stay, number of
NPWTs, and flaps used between the two cohorts. This highlights how the local control and toxicity benefit in SR may offset the initially higher hospital stay and number of procedures, allowing for an improvement in cost at 18 months.

In our study, patients undergoing amputation had no significant increase in treatment cost at 18 months, but this could be due to an underpowered study or inability to effectively capture longer term expenses associated with an amputation. In previous studies, the largest cost burden with amputation is secondary to prosthesis maintenance $[6,33,34,35]$. Amputation compared to reconstruction surgery can have up to 3 times the cost over a patient's lifetime [33]. The follow-up required to account for the long-term cost contribution of amputation, is a limitation of our study. In our previous study, the local control and toxicity benefit in SR translated into a limb preservation improvement ( $88 \%$ vs. $50 \%, p=0.008$ ) [20]. With improved limb preservation in SR, we predict that longer follow-up would show an even larger healthcare cost benefit in favor of SR. In addition to cost, SR also had trending improvements in toxicity, chronic pain, and limb preservation. Though our study did not formally assess quality of life surveys, subjective complications abstracted from the patient chart can give us insight into patient's quality of life after treatment. This study was grossly underpowered to detect a toxicity or limb preservation benefit in SR, as was noted before [20]. Overall, we believe that SR can offer high local control in recurrent STS, while improving patient toxicity and cost, when compared to IR.

The limitations of this study are that it is retrospective in nature and therefore subject to selection bias, since we cannot accurately account for all the factors influencing the decision for immediate vs. staged reconstruction. Also, our institution does not have a prosthetics department, which precludes the cost associated with amputations from being included in the analysis. While the length of follow-up may be of concern, all recurrences occurred within 18 months, and majority of the costs associ- 
A

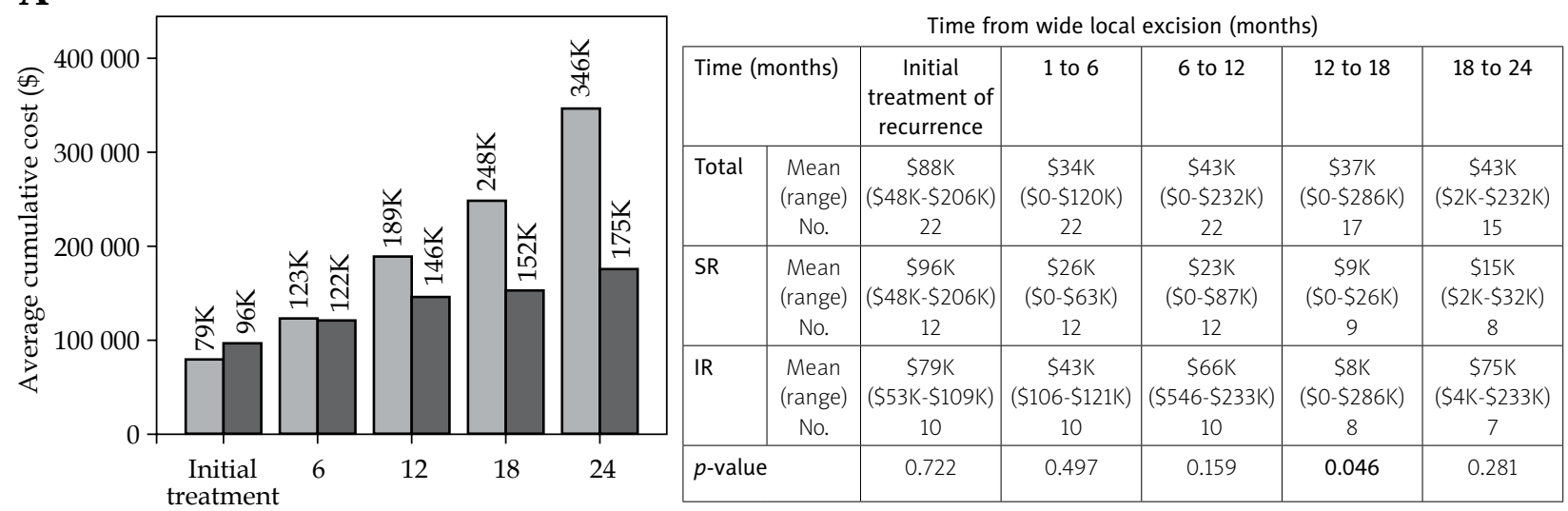

of recurrence

\section{B}

$\square$ Immediate $\quad \square$ Staged

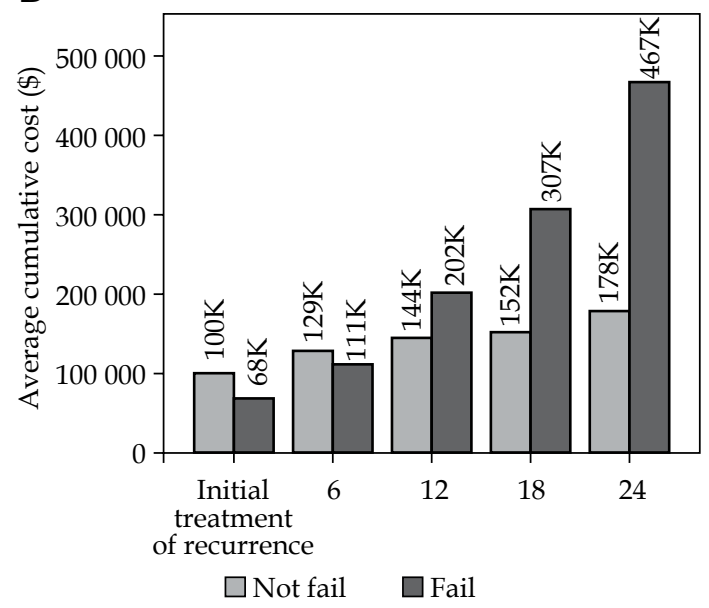

\begin{tabular}{|c|c|c|c|c|c|}
\hline \multicolumn{6}{|c|}{ Time from wide local excision (months) } \\
\hline \multicolumn{2}{|c|}{ Time (months) } & 1 to 6 & 6 to 12 & 12 to 18 & 18 to 24 \\
\hline $\begin{array}{l}\text { No local } \\
\text { failure }\end{array}$ & $\begin{array}{c}\text { Mean } \\
\text { (range) } \\
\text { No. }\end{array}$ & $\begin{array}{c}\$ 29 K \\
(\$ 0-\$ 63 K) \\
14\end{array}$ & $\begin{array}{c}\$ 16 K \\
(\$ 0-\$ 44 K) \\
14\end{array}$ & $\begin{array}{c}\$ 10 K \\
(\$ 0-\$ 26 K) \\
12\end{array}$ & $\begin{array}{c}\$ 20 K \\
\$ 13 K(\$ 4 K-\$ 63 K) \\
11\end{array}$ \\
\hline $\begin{array}{l}\text { Local } \\
\text { failure }\end{array}$ & $\begin{array}{c}\text { Mean } \\
\text { (range) } \\
\text { No. }\end{array}$ & $\begin{array}{c}\$ 43 \mathrm{~K} \\
(\$ 106-\$ 121 \mathrm{~K}) \\
8\end{array}$ & $\begin{array}{c}\$ 90 K \\
(\$ 546-\$ 233 K) \\
8\end{array}$ & $\begin{array}{c}\$ 101 K \\
(\$ 5-\$ 286 K) \\
5\end{array}$ & $\begin{array}{c}\$ 105 K \\
(\$ 2 K-\$ 233 K) \\
3\end{array}$ \\
\hline$p$-value & & 1 & 0.003 & 0.279 & 0.949 \\
\hline $\begin{array}{l}\text { Events } \\
\text { Cumulative } \\
\text { events }\end{array}$ & $\begin{array}{l}\text { No. } \\
\text { No. }\end{array}$ & $\begin{array}{l}3 \\
3\end{array}$ & $\begin{array}{l}4 \\
7\end{array}$ & $\begin{array}{l}1 \\
8\end{array}$ & $\begin{array}{l}0 \\
8\end{array}$ \\
\hline
\end{tabular}

C

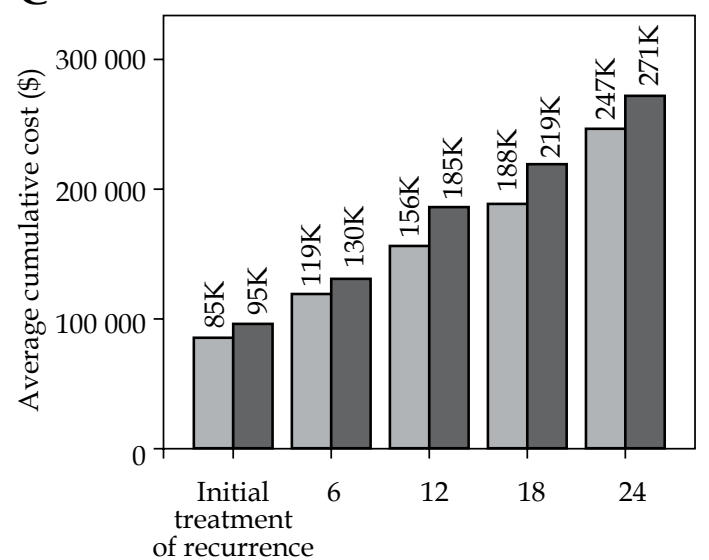

\begin{tabular}{|c|c|c|c|c|c|}
\hline \multicolumn{6}{|c|}{ Time from wide local excision (months) } \\
\hline \multicolumn{2}{|c|}{ Time (months) } & 1 to 6 & 6 to 12 & 12 to 18 & 18 to 24 \\
\hline $\begin{array}{l}\text { No ampu- } \\
\text { tation }\end{array}$ & $\begin{array}{c}\text { Mean } \\
\text { (range) } \\
\text { No. }\end{array}$ & $\begin{array}{c}\$ 34 \mathrm{~K} \\
(\$ 0-\$ 107 \mathrm{~K}) \\
15\end{array}$ & $\begin{array}{c}\$ 37 K \\
(\$ 546-\$ 233 K) \\
15\end{array}$ & $\begin{array}{c}\$ 34 K \\
(\$ 0-\$ 286 K) \\
12\end{array}$ & $\begin{array}{c}\$ 39 K \\
(\$ 4 K-\$ 233 K) \\
10\end{array}$ \\
\hline $\begin{array}{l}\text { Amputa- } \\
\text { tion }\end{array}$ & $\begin{array}{c}\text { Mean } \\
\text { (range) } \\
\text { No. }\end{array}$ & $\begin{array}{c}\$ 35 \mathrm{~K} \\
(\$ 231-\$ 121 \mathrm{~K}) \\
7\end{array}$ & $\begin{array}{c}\$ 55 \mathrm{~K} \\
(\$ 0-\$ 138 \mathrm{~K}) \\
7\end{array}$ & $\begin{array}{c}\$ 44 K \\
(\$ 5 K-\$ 184 K) \\
5\end{array}$ & $\begin{array}{c}\$ 52 \mathrm{~K} \\
(\$ 2 \mathrm{~K}-\$ 183 \mathrm{~K}) \\
4\end{array}$ \\
\hline \multicolumn{2}{|l|}{$p$-value } & 1 & 0.332 & 0.959 & 0.594 \\
\hline $\begin{array}{l}\text { Events } \\
\text { Cumulative } \\
\text { events }\end{array}$ & $\begin{array}{l}\text { No. } \\
\text { No. }\end{array}$ & $\begin{array}{l}2 \\
2\end{array}$ & $\begin{array}{l}4 \\
6\end{array}$ & $\begin{array}{l}1 \\
7\end{array}$ & $\begin{array}{l}0 \\
7\end{array}$ \\
\hline
\end{tabular}

$\square$ No amputation

$\square$ Amputation

Fig. 2. Comparison of cost for patients with A) staged reconstruction (SR) vs. immediate reconstruction (IR), B) local failure vs. no local failure, and C) amputation vs. no amputation

ated were likely accounted for with our studies length of follow-up (median 31 months).

\section{Conclusions}

Surgical resection and adjuvant brachytherapy are an effective treatment for recurrent STS. When comparing treatments with similar survival, it is important to also evaluate toxicity, disease control, quality of life, and cost. Staged reconstruction may be less convenient and may have higher initial cost, but the toxicity and local control benefit from this technique allows for a decreased total cost at 18 months. In addition, there is evidence that staged reconstruction brachytherapy may offer improved 


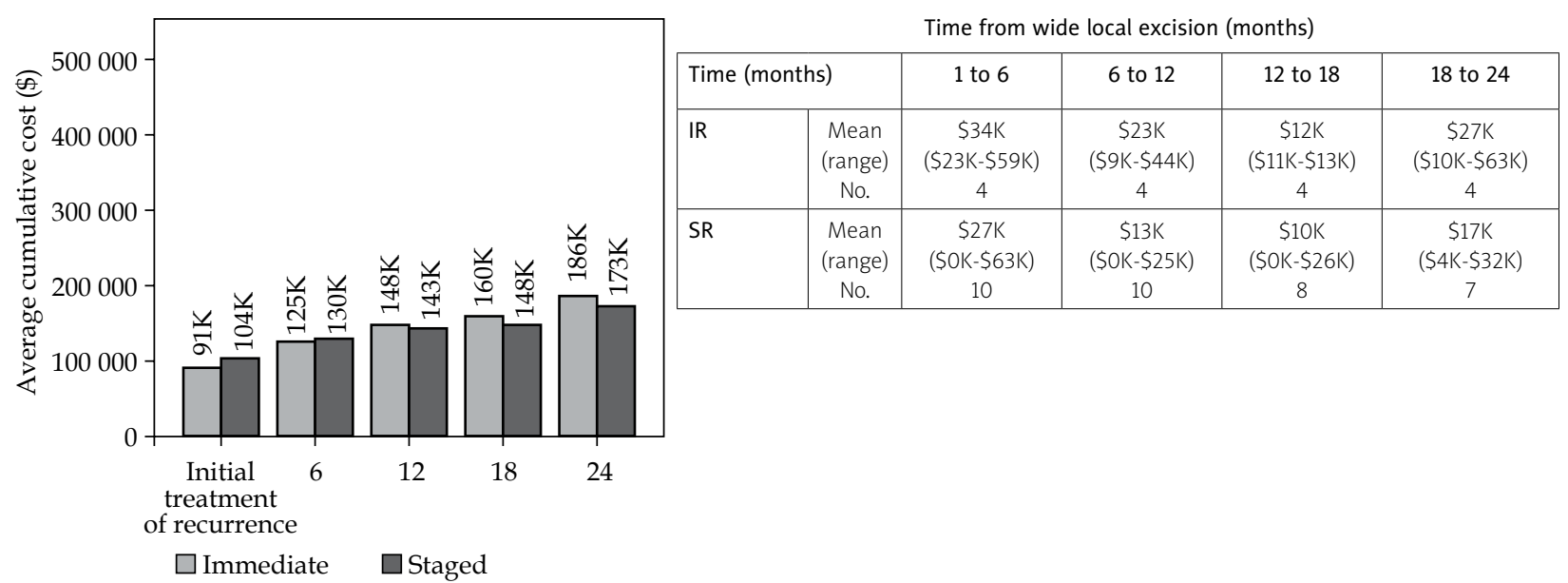

Fig. 3. Comparing staged reconstruction (SR) and immediate reconstruction (IR) cost in patients with no local failure

toxicity, disease control, and limb preservation. This, in turn, may translate into improved patient quality of life with the potential for decreased lifetime costs associated with amputation, such as prosthesis maintenance. Therefore, this study suggests that SR is the more cost-effective brachytherapy approach in the treatment of STS, and should be considered as healthcare transitions into value-based medicine. Future studies that focus on cost should randomize patients to staged or immediate reconstruction to reduce selection bias.

\section{Disclosure}

Authors report no conflict of interest.

\section{References}

1. Lindberg RD, Martin RG, Romsdahl MM et al. Conservative surgery and postoperative radiotherapy in 300 adults with soft-tissue sarcomas. Cancer 1981; 47: 2391-2397.

2. Rosenberg SA, Tepper J, Glatstein E et al. The treatment of soft-tissue sarcomas of the extremities: prospective randomized evaluations of (1) limb-sparing surgery plus radiation therapy compared with amputation and (2) the role of adjuvant chemotherapy. Ann Surg 1982; 196: 305-315.

3. Tepper J, Rosenberg SA, Glatstein E. Radiation therapy technique in soft tissue sarcomas of the extremity - policies of treatment at the National Cancer Institute. Int J Radiat Oncol Biol Phys 1982; 8: 263-273.

4. Tepper JE, Suit HD. The role of radiation therapy in the treatment of sarcoma of soft tissue. Cancer Invest 1985; 3: 587-592.

5. Papagelopoulos PJ, Mavrogenis AF, Mastorakos DP et al. Current concepts for management of soft tissue sarcomas of the extremities. J Surg Orthop Adv 2008; 17: 204-215.

6. Grimer RJ, Carter SR, Pynsent PB. The cost-effectiveness of limb salvage for bone tumours. J Bone Joint Surg Br 1997; 79: 558-561.

7. Janjan NA, Yasko AW, Reece GP et al. Comparison of charges related to radiotherapy for soft-tissue sarcomas treated by preoperative external-beam irradiation versus interstitial implantation. Ann Surg Oncol 1994; 1: 415-422.

8. Pisters PW, Harrison LB, Leung DH et al. Long-term results of a prospective randomized trial of adjuvant brachytherapy in soft tissue sarcoma. J Clin Oncol 1996; 14: 859-868.

9. Indelicato DJ, Meadows K, Gibbs CP, Jr. et al. Effectiveness and morbidity associated with reirradiation in conservative salvage management of recurrent soft-tissue sarcoma. Int J Radiat Oncol Biol Phys 2009; 73: 267-272.

10. Spierer MM, Alektiar KM, Zelefsky MJ et al. Tolerance of tissue transfers to adjuvant radiation therapy in primary soft tissue sarcoma of the extremity. Int J Radiat Oncol Biol Phys 2003; 56: 1112-1116.

11. Arbeit JM, Hilaris BS, Brennan MF. Wound complications in the multimodality treatment of extremity and superficial truncal sarcomas. J Clin Oncol 1987; 5: 480-488.

12. Torres MA, Ballo MT, Butler CE et al. Management of locally recurrent soft-tissue sarcoma after prior surgery and radiation therapy. Int J Radiat Oncol Biol Phys 2007; 67: 1124-1129.

13. Nori D, Schupak K, Shiu MH et al. Role of brachytherapy in recurrent extremity sarcoma in patients treated with prior surgery and irradiation. Int J Radiat Oncol Biol Phys 1991; 20: 1229-1233.

14. Pearlstone DB, Janjan NA, Feig BW et al. Re-resection with brachytherapy for locally recurrent soft tissue sarcoma arising in a previously radiated field. Cancer J Sci Am 1999; 5: 26-33.

15. Emory CL, Montgomery CO, Potter BK et al. Early complications of high-dose-rate brachytherapy in soft tissue sarcoma: a comparison with traditional external-beam radiotherapy. Clin Orthop Relat Res 2012; 470: 751-758.

16. Alamanda VK, Delisca GO, Mathis SL et al. The financial burden of reexcising incompletely excised soft tissue sarcomas: a cost analysis. Ann Surg Oncol 2013; 20: 2808-2814.

17. Heinz TR, Cowper PA, Levin LS. Microsurgery costs and outcome. Plast Reconstr Surg 1999; 104: 89-96.

18. Nelson AA, Frassica FJ, Gordon TA et al. Cost analysis of functional restoration surgery for extremity soft-tissue sarcoma. Plast Reconstr Surg 2006; 117: 277-283.

19. Sakellariou VI, Mavrogenis AF, Papagelopoulos PJ. Negativepressure wound therapy for musculoskeletal tumor surgery. Adv Skin Wound Care 2011; 24: 25-30.

20. Naghavi AO, Gonzalez R, Scott JG et al. Implications of Staged Reconstruction and Adjuvant Brachytherapy in the Treatment of Recurrent Soft Tissue Sarcoma. Brachytherapy 2016; 15: 495-503.

21. Petruzzelli GJ, Brockenbrough JM, Vandevender D et al. The influence of reconstructive modality on cost of care in head and neck oncologic surgery. Arch Otolaryngol Head Neck Surg 2002; 128: 1377-1380.

22. Heller L, Ballo MT, Cormier JN et al. Staged reconstruction for resection wounds in sarcoma patients treated with brachytherapy. Ann Plast Surg 2008; 60: 58-63. 
23. Kopp J, Strnad V, Bach AD et al. Vacuum application increases therapeutic safety and allows intensified local radiation treatment of malignant soft-tissue tumors. Strahlenther Onkol 2005; 181: 124-130.

24. Rudert M, Winkler C, Holzapfel BM et al. A new modification of combining vacuum therapy and brachytherapy in large subfascial soft-tissue sarcomas of the extremities. Strahlenther Onkol 2010; 186: 224-228.

25. Senchenkov A, Clay RP. Vacuum-Assisted Closure (VAC) dressing as a temporary coverage for brachytherapy afterloading catheters. Ann Plast Surg 2006; 57: 355.

26. Alektiar KM, Zelefsky MJ, Brennan MF. Morbidity of adjuvant brachytherapy in soft tissue sarcoma of the extremity and superficial trunk. Int J Radiat Oncol Biol Phys 2000; 47: 1273-1279.

27. Morykwas MJ, Argenta LC, Shelton-Brown EI et al. Vacuum-assisted closure: a new method for wound control and treatment: animal studies and basic foundation. Ann Plast Surg 1997; 38: 553-562.

28. Argenta LC, Morykwas MJ. Vacuum-assisted closure: a new method for wound control and treatment: clinical experience. Ann Plast Surg 1997; 38: 563-576; discussion 577.

29. Ballo MT, Zagars GK, Cormier JN et al. Interval between surgery and radiotherapy: effect on local control of soft tissue sarcoma. Int J Radiat Oncol Biol Phys 2004; 58: 1461-1467.

30. Schwartz DL, Einck J, Hunt K et al. The effect of delayed postoperative irradiation on local control of soft tissue sarcomas of the extremity and torso. Int J Radiat Oncol Biol Phys 2002; 52: 1352-1359.

31. Wackenfors A, Gustafsson R, Sjögren J et al. Blood flow responses in the peristernal thoracic wall during vacuum-assisted closure therapy. Ann Thorac Surg 2005; 79: 1724-1730; discussion 1730-1731.

32. Harrison L, Blackwell K. Hypoxia and anemia: factors in decreased sensitivity to radiation therapy and chemotherapy? Oncologist 2004; 9 Suppl 5: 31-40.

33. MacKenzie EJ, Jones AS, Bosse MJ et al. Health-care costs associated with amputation or reconstruction of a limb-threatening injury. J Bone Joint Surg Am 2007; 89: 1685-1692.

34. Hertel R, Strebel N, Ganz R. Amputation versus reconstruction in traumatic defects of the leg: outcome and costs. J Orthop Trauma 1996; 10: 223-229.

35. Kadam D. Limb salvage surgery. Indian J Plast Surg 2013; 46: 265-274. 